BMJ Open Sport \& Exercise Medicine

\section{Health-related physical fitness in patients with complaints of hand, wrist, forearm and elbow: an exploratory study}

To cite: Berduszek RJ, Geerdink $\mathrm{H}$, van der Sluis CK, et al. Health-related physical fitness in patients with complaints of hand, wrist, forearm and elbow: an exploratory study. BMJ Open Sport \& Exercise Medicine 2021;7:e01148. doi:10.1136/

Accepted 6 September 2021 bmjsem-2021-001148

\section{ABSTRACT}

Objectives Little is known about the physical fitness of patients with complaints of hand, wrist, forearm and/ or elbow and its possible determinants. Aims were to assess health-related physical fitness (HRPF) in these patients, to compare HRPF with reference values of healthy persons, and to explore whether HRPF was correlated with symptom severity, upper limb function (ULF) and physical activity (PA)

Methods Cardiorespiratory fitness, handgrip strength and body composition, self-reported symptom severity, ULF and PA were assessed in adult outpatients with complaints of hand, wrist, forearm and/or elbow diagnosed as CANS.

Results Measurements were completed in 25 subjects (8 males) aged $46.1 \pm 14.5$ years, of which $44 \%$ had specific CANS and $56 \%$ had non-specific CANS.

Peak oxygen consumption ( $\mathrm{VO}_{2}$ peak) of men was $2978 \pm 983 \mathrm{~mL} / \mathrm{min}$ and of women was $1978 \pm 265 \mathrm{~mL} /$ min. Handgrip strength of men was $47.0 \pm 11.1 \mathrm{kgf}$ and of women was $32.4 \pm 6.3 \mathrm{kgf}$. Body mass index (BMI) of men was $24.2 \pm 2.6 \mathrm{~kg} / \mathrm{m}^{2}$ and of women was $27.4 \pm 6.1 \mathrm{~kg} / \mathrm{m}^{2}$. V0 ${ }_{2}$ peak of the study sample was lower than that of healthy adults $(-414 \pm 510 \mathrm{~mL} / \mathrm{min}, \mathrm{p}<0.001)$. Handgrip strength and $\mathrm{BMI}$ were similar to reference values. V0 peak was correlated with PA ( $r=0.58, p=0.004)$; $B M I$ was correlated with disability $(r=0.48, p=0.022)$. Other correlations between HRPF and symptom severity and ULF were non-significant.

Conclusions Patients with CANS have lower cardiorespiratory fitness, but similar handgrip strength and body composition, compared with the healthy population. Cardiorespiratory fitness was correlated with PA and BM was correlated with disability, no other correlations were observed with symptom severity and ULF.

\section{(C) Author(s) (or their} employer(s)) 2021. Re-use permitted under CC BY-NC. No commercial re-use. See rights and permissions. Published by BMJ.

Department of Rehabilitation Medicine, University of Groningen, University Medical Center Groningen, Groningen, The Netherlands

Correspondence to Redmar J Berduszek; r.j.berduszek@umcg.nl

\section{INTRODUCTION}

Upper limb disorders, such as complaints of arm, neck and/or shoulder (CANS), occur frequently and may lead to pain and disability. ${ }^{1}$ CANS are musculoskeletal complaints of arm, neck and shoulder not caused by acute trauma or by any systemic disease. The point prevalence of CANS in the Netherlands is over 25\%. ${ }^{12}$ These disorders can result in limitations in a broad range of daily activities, such as work, hobbies and sports. ${ }^{3}$ To be able

\section{Key messages}

What are the new findings

- Cardiorespiratory fitness of patients with complaints of arm, neck and/or shoulder (CANS) was lower than expected from reference values.

- There was no evident relationship between healthrelated physical fitness (HRPF) and symptom severity and hand function.

- Cardiorespiratory fitness was better in subjects meeting national physical activity (PA) guidelines.

How might it impact on clinical practice in the near future

- Physicians and therapists should pay attention to HRPF (especially cardiorespiratory fitness) in patients with CANS.

- While the causal relationship is still unknown, interventions to improve PA (frequency, duration and intensity to meet the Fitnorm) should be considered.

to carry out the desired combination of those daily activities, one has to be physically fit. ${ }^{4}$ However, little is known about the physical fitness in patients with CANS.

Physical fitness is defined as a set of attributes or characteristics individuals have or achieve that relates to their ability to perform physical activity. These characteristics are usually separated into health-related and skill-related components of physical fitness. Health-related physical fitness components are cardiorespiratory endurance, muscular strength, muscular endurance, body composition and flexibility. ${ }^{4}$ Cardiorespiratory endurance is the ability of the heart and lungs to supply oxygen during sustained physical activity. Muscular strength is the ability to exert force, and muscular endurance is the ability to continue to perform without fatigue. Body composition is the relative amount of muscle, fat, bone and other vital parts of the body. Flexibility is the range of motion available at the joints. Skill-related physical fitness is important for performing 
the more technical aspects of many sports, such as agility, balance, coordination, power, reaction time and speed.

Health-related fitness components, especially cardiorespiratory endurance, muscular strength and muscular endurance, are consistently lower in patients with various chronic musculoskeletal complaints. ${ }^{5-8}$ Lower levels of physical fitness are related with both lower levels of physical activity and the presence of musculoskeletal complaints. ${ }^{6910}$ Physical inactivity is also associated with the development of chronic CANS. ${ }^{11}$ However, objectively measured physical fitness of patients with CANS has not been studied yet, nor has the relation between physical fitness and symptom severity and disability.

The primary aim of this exploratory study was to describe objectively measured health-related physical fitness in patients with complaints of hand, wrist, forearm and elbow (focusing on cardiorespiratory fitness, muscular strength and body composition). Secondary aims were to compare their health-related physical fitness with reference values of healthy persons, and to explore whether their health-related physical fitness was correlated with self-reported symptom severity and upper limb function and physical activity.

\section{METHODS}

This cross-sectional study was performed at the Department of Rehabilitation Medicine of the University Medical Center Groningen, the Netherlands, between January 2016 and May 2017. All subjects gave written informed consent.

\section{Participants}

Eligible subjects were outpatients visiting our department, aged $\geq 18$ years and suffering from complaints of hand, wrist, forearm and/or elbow classified as CANS. ${ }^{2}$ Exclusion criteria were inadequate knowledge of Dutch language and the presence of other medical conditions causing considerable disability, such as neurological disorders or joint diseases. Subjects did not need to receive treatment for CANS, nor were they excluded if they did. All subjects were screened for the presence of contraindications for a cardiopulmonary exercise test (CPET) based on the ATS/ACCP statement on cardiopulmonary exercise testing. ${ }^{12}$ While we were unable to calculate a sample size for this exploratory study, because necessary data were lacking, we aimed to include at least 25 subjects as a non-probability convenience sample. ${ }^{13}$

\section{Measurements}

During a single visit to the exercise laboratory of our department, measurements were taken to assess healthrelated physical fitness (cardiorespiratory fitness, muscular strength and body composition). Questionnaires to assess demographic, clinical and social characteristics, symptom severity and upper limb function and physical activity were filled out in the week prior to visiting the exercise laboratory.

\section{Health-related physical fitness}

\section{Cardiorespiratory fitness}

The gold standard for cardiorespiratory fitness is maximum oxygen consumption $\left(\mathrm{VO}_{2} \max \right)$. For practical reasons, usually the highest achieved $\mathrm{VO}_{2}$ during a CPET is used, termed $\mathrm{VO}_{2}$ peak. $\mathrm{VO}_{2}$ peak can be used as an estimate for $\mathrm{VO}_{2}$ max and these units are used interchangeably. ${ }^{12}$

To measure $\mathrm{VO}_{2}$ peak $(\mathrm{mL} / \mathrm{min}$ and $\mathrm{mL} / \mathrm{min} / \mathrm{kg})$, subjects performed a CPET on a cycle ergometer. A maximal incremental ergometry protocol was used, consisting of $1 \mathrm{~min}$ of rest, followed by $3 \mathrm{~min}$ of cycling without resistance, followed by a phase of increasing resistance. ${ }^{12}$ This phase started with $10 \mathrm{~W}, 15 \mathrm{~W}, 20 \mathrm{~W}$ or $25 \mathrm{~W}$ and increased continuously with $10 \mathrm{~W}, 15 \mathrm{~W}$ or 20 W every 1 min (ramp protocol) until symptom limitation (eg, exhaustion, breathlessness or leg discomfort) or test termination by the monitor. Both starting resistance and the incremental rate were dependent on the monitor's appraisal. CPET duration is about $8-12 \mathrm{~min}$ from the start of cycling with resistance. All tests were monitored by a certified exercise physiologist. Maximal effort was determined by a respiratory exchange ratio (RER) of $>1.1$ and/or maximum heart rate (HR) of $>85 \%$ of predicted HR (maximum predicted $\mathrm{HR}=220$-age (in years)).

Two sets of reference values were chosen. First, reference values based on the best-fitting polynomial regression model which was determined using cycle ergometry in a healthy Dutch population. ${ }^{14}$ The equation of this model is $\mathrm{VO}_{\text {o }}$ eak $=-1469+(673.00 \times$ sex $)+(16.87 \times$ age $($ in years $))$ $+\left(-0.47 \times\right.$ age $\left.\left.^{2}\right)+(0.07 \times \text { height (in centimetres })^{2}\right)+(39.70 \times-$ weight (in kilogrammes) $)+\left(-0.16 \times\right.$ weight $\left.^{2}\right)$, where male $=1$ and female $=0$. Second, the reference values of the American College of Sports Medicine (ACSM), which categorises cardiorespiratory fitness into one of six categories ranging from very poor to superior. ${ }^{15}$ ACSM categories are based on $\mathrm{VO}_{2} \max$ and dependent of sex and age.

\section{Muscular strength (handgrip strength)}

Handgrip strength (kgf) was measured with a digital dynamometer (JAMAR Plus + digital hand dynamometer) in grip position $2 .{ }^{16}$ The test was performed for both hands separately in the sitting position. The subjects were asked to hold the dynamometer parallel to the side of the body and the elbow in $90^{\circ}$ and squeeze the handgrip dynamometer as hard as possible. The test was repeated three times for each hand, the maximum of these values was used (not necessarily of the dominant or affected hand). Reference values from a large British population were used for comparison, stratified by sex and age. ${ }^{17}$

\section{Body composition}

Body mass index (BMI) is defined as a person's weight in kilogrammes divided by the square of the person's height in metres $\left(\mathrm{kg} / \mathrm{m}^{2}\right)$. BMI was calculated using measurements of weight (wearing underwear only) and height (without shoes and socks). BMI is categorised as 


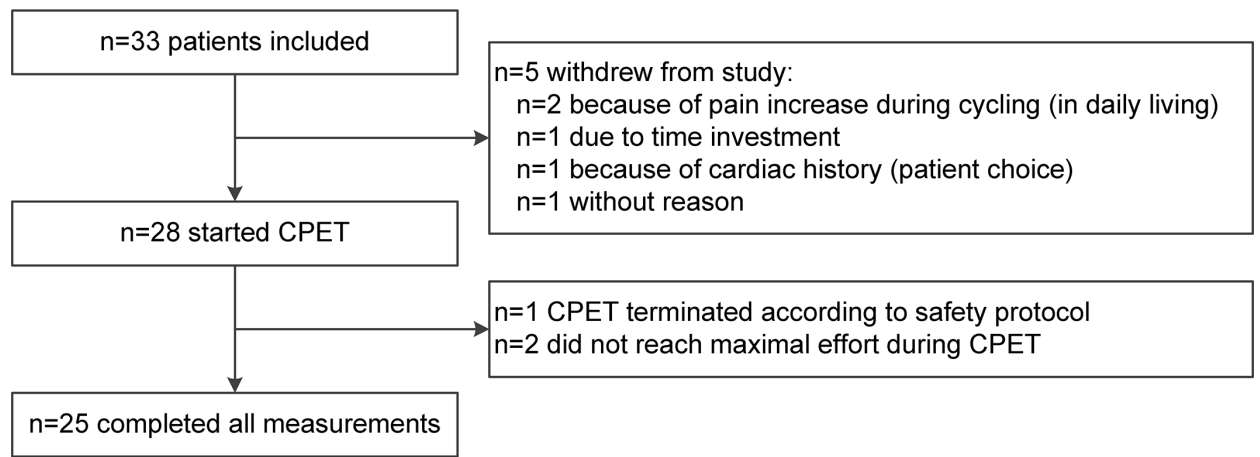

Figure 1 Selection of participants. CPET, cardiopulmonary exercise test.

underweight $\left(<18.5 \mathrm{~kg} / \mathrm{m}^{2}\right)$, normal weight (18.5-24.9 $\left.\mathrm{kg} / \mathrm{m}^{2}\right)$, overweight $\left(25.0-29.9 \mathrm{~kg} / \mathrm{m}^{2}\right)$ and obesity $(\geq 30$ $\left.\mathrm{kg} / \mathrm{m}^{2}\right) .{ }^{18}$ BMI categories based on self-reported height and weight by Dutch adults in 2017 were used as reference values. $^{19}$

Fat-free mass (FFM) was assessed by bioelectrical impedance analysis, using the BIA 101 Anniversary Sport Edition and Bodygram Plus software (Akern Srl, Italy). Fat-Free Mass Index (FFMI), the height-normalised index of FFM, was calculated by dividing FFM by height squared $\left(\mathrm{kg} / \mathrm{m}^{2}\right)$. FFMI was assessed because BMI alone does not provide detailed information about body composition with regard to FFM and fat mass. ${ }^{20}$ Reference values were derived from a study reporting FFMI of healthy Caucasian adults. ${ }^{21}$

\section{Demographic, clinical and social characteristics}

Patient characteristics

Subjects filled out a questionnaire with several questions about patient characteristics, including marital status, education, work, dominant arm and affected side. Diagnosis and duration of complaints were extracted from the electronic health record.

\section{RAND-36}

RAND-36 is a 36-item questionnaire about physical, mental and social health and is used worldwide to measure health-related quality of life, which has been shown to be reliable and valid. ${ }^{22}$ RAND-36 consists of eight subscales measuring either physical or mental health. Subscale scores (scale: $0-100$ ) are calculated using an algorithm. ${ }^{23}$ Higher scores reflect a better health status.

\section{Symptom severity and upper limb function}

Quick Disabilities of the Arm, Shoulder and Hand Questionnaire

The Quick Disabilities of the Arm, Shoulder and Hand (QuickDASH) ${ }^{24}$ Questionnaire (scale: $0-100$ ) is a selfreported questionnaire designed to measure physical function and symptoms in patients with musculoskeletal disorders of the upper limb. A higher score indicates a greater symptom severity.

Patient-Rated Wrist/Hand Evaluation Questionnaire

The Patient-Rated Wrist/Hand Evaluation (PRWHE) ${ }^{25}$ Questionnaire (scale: $0-100$ ) is a self-reported questionnaire developed to assess pain and functional difficulties in activities of daily living during last week due to hand or wrist disorders. A higher score indicates more pain and a greater symptom severity.

\section{Pain Disability Index}

The Pain Disability Index (PDI) ${ }^{27}$ (scale: $0-70$ ) is a selfreported questionnaire focusing on the impact of pain on a person's ability to participate in essential life activities. A higher score indicates a greater disability in daily activities.

\section{Numeric Pain Rating Scale}

The Numeric Pain Rating Scale (NRS-Pain) (scale: 0-10) is a self-reported questionnaire to rate pain during the last week on an 11-point scale ranging from 'no pain' to 'worst pain imaginable'. ${ }^{28} \mathrm{~A}$ higher score indicates a greater pain severity.

\section{Physical activity}

\section{Nederlandse Norm Gezond Bewegen}

The Nederlandse Norm Gezond Bewegen (NNGB, in English: Dutch Healthy Physical Activity Guidelines) advises on the minimal amount of physical activity to maintain and improve health. ${ }^{29}$ In the NNGB, adults are advised to perform physical activity at least $30 \mathrm{~min} /$ day, at least at moderate intensity, at least 5 days/week. Subjects were asked if they met the criteria of the NNGB.

\section{Fitnorm}

The Dutch Fitnorm is based on recommendations about quantity and quality of exercise for developing and maintaining fitness in healthy adults. ${ }^{30}$ To meet the Fitnorm, a person needs to exercise at least three times a week for $20 \mathrm{~min}$ at vigorous intensity. Subjects were asked if they met the criteria of the Fitnorm.

\section{Statistical analyses}

Descriptive statistics were used to describe measured components of health-related physical fitness, demographic information, symptom severity and upper limb function and physical activity. Continuous variables were presented as mean \pm SD. Categorical data were presented as frequency and percentage. 
Table 1 Participant characteristics $(n=25)$

\begin{tabular}{|c|c|}
\hline \multicolumn{2}{|l|}{ Sex, n (\%) } \\
\hline Male & $8(32)$ \\
\hline Age, mean $\pm \mathrm{SD}$ (years) & $46.1 \pm 14.5$ \\
\hline \multicolumn{2}{|l|}{ Duration of complaints, $\mathrm{n}(\%)$} \\
\hline$<3$ months & $0(0)$ \\
\hline $3-6$ months & $1(4)$ \\
\hline 6-12 months & $9(32)$ \\
\hline$>12$ months & $18(64)$ \\
\hline \multicolumn{2}{|l|}{ Dominant arm, n (\%) } \\
\hline Right & $18(72)$ \\
\hline Left & $6(24)$ \\
\hline Two-handed & $1(4)$ \\
\hline \multicolumn{2}{|l|}{ Affected arm, n (\%) } \\
\hline Right & $7(28)$ \\
\hline Left & $3(12)$ \\
\hline Both & $15(60)$ \\
\hline \multicolumn{2}{|l|}{ Diagnosis, n (\%) } \\
\hline Specific CANS & $11(44)$ \\
\hline Trigger finger & 4 \\
\hline De Quervain's disease & 3 \\
\hline Lateral epicondylitis & 2 \\
\hline Dupuytren disease & 2 \\
\hline Non-specific CANS & $14(56)$ \\
\hline \multicolumn{2}{|l|}{ Employed, n (\%) } \\
\hline Yes & $16(64)$ \\
\hline \multicolumn{2}{|l|}{ Current sick leave from work, $\mathrm{n}(\%)$} \\
\hline Yes & $4(16)$ \\
\hline \multicolumn{2}{|l|}{ RAND-36, mean \pm SD } \\
\hline Physical functioning & $77.2 \pm 21.2$ \\
\hline Social functioning & $76.5 \pm 26.3$ \\
\hline Role limitations (physical problems) & $54.0 \pm 32.0$ \\
\hline Role limitations (emotional problems) & $70.3 \pm 29.7$ \\
\hline Mental health & $66.0 \pm 18.4$ \\
\hline Vitality & $52.3 \pm 18.5$ \\
\hline Pain & $58.1 \pm 17.8$ \\
\hline General health perception & $57.6 \pm 22.2$ \\
\hline
\end{tabular}

Symptom severity and upper limb function, mean $\pm S D$

\begin{tabular}{ll}
\hline QuickDASH Questionnaire & $28.2 \pm 15.7$ \\
\hline PRWHE Questionnaire & $36.6 \pm 20.6$ \\
\hline PDI & $17.8 \pm 14.0$ \\
\hline NRS-Pain & $3.9 \pm 2.1$ \\
\hline Physical activity, $n(\%)$ & \\
\hline NNGB (meeting criteria) & $17(68 \%)$ \\
\hline Fitnorm (meeting criteria) & $8(32 \%)$ \\
\hline
\end{tabular}

Criteria for meeting NNGB: perform physical activity at least $30 \mathrm{~min} /$ day, at least at moderate intensity, at least 5 days/week.

Criteria for meeting Fitnorm: exercise at least three times a week for $20 \mathrm{~min}$ at vigorous intensity.

CANS, complaints of arm, neck and/or shoulder; NNGB, Nederlandse Norm Gezond Bewegen (Dutch Healthy Physical Activity Guidelines); NRS-Pain, Numeric Pain Rating Scale; PDI, Pain Disability Index; PRWHE, Patient-Rated Wrist/Hand Evaluation; QuickDASH, Quick Disabilities of the Arm, Shoulder and Hand.
Cardiorespiratory fitness of the study sample was compared with reference values based on the bestfitting polynomial regression model. Using the equation mentioned above, the reference value (predicted $\mathrm{VO}_{2} \max$ ) was calculated for each subject, the mean of which was compared with the tested group using a paired t-test. Comparison of handgrip strength and body composition with reference values was reported using descriptive statistics. Spearman's partial correlations analyses were calculated between health-related fitness components and possible determining variables (controlling for sex and age). ${ }^{31}{ }^{32}$ The sample size was deemed too small to perform a multivariate regression analysis. Correlation coefficients were interpreted as negligible $(0.00-0.10)$, weak $(0.10-0.30)$, moderate $(0.30-0.70)$, strong $(0.70-0.90)$ or very strong $(0.90-1.00) .{ }^{33}$ The level of significance was set at $\mathrm{p}<0.05$. Statistical analyses were performed using IBM SPSS Statistics for Windows, V.23.0.

\section{RESULTS \\ Participants}

In total, 33 subjects were included (figure 1). Five subjects withdrew before taking measurements and the CPET of one subject was terminated by the monitor before symptom limitation because of hypertension. Two subjects did not reach maximal effort during CPET (based on RER and maximum HR values) and were subsequently excluded from analyses concerning cardiorespiratory fitness using $\mathrm{VO}_{2}$ peak. Therefore, 25 subjects completed all measurements (table 1). The majority of the sample $(68 \%)$ was female. Mean age of the total sample was $46.1 \pm 14.5$ years $(44.3 \pm 16.4$ years for men and $46.9 \pm 13.9$ years for women). Complaints were diagnosed as specific CANS in $44 \%$ of subjects and as non-specific CANS in $56 \%$ of subjects. The mean QuickDASH score of the total sample was $28.2 \pm 15.7$ (22.2 \pm 10.6 for men and $31.0 \pm 17.2$ for women) and the mean PRWHE score of the total sample was $36.6 \pm 20.6$ (29.8 \pm 14.3 for men and $39.9 \pm 22.6$ for women).

Three adverse events were reported, it concerned ECG abnormalities at maximal effort without further symptoms in all cases. In all three subjects, the ECG abnormalities resolved spontaneously after reducing effort. Subjects were advised to contact their general practitioner for further review and consider assessment by a cardiologist. No serious adverse events occurred during this study.

\section{Health-related physical fitness: description and comparison with reference values}

A detailed overview of the results of all measured aspects of health-related physical fitness (cardiorespiratory fitness, handgrip strength and body composition) for each subject is presented in table 2 .

\section{Cardiorespiratory fitness}

Mean $\mathrm{VO}_{2}$ peak of the study sample was $2298 \pm 745 \mathrm{~mL} /$ min. According to the model to calculate individual reference values, the mean $\mathrm{VO}_{2}$ peak was expected to be 


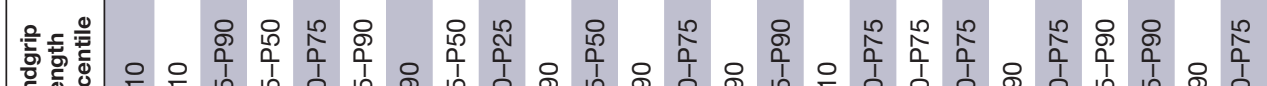

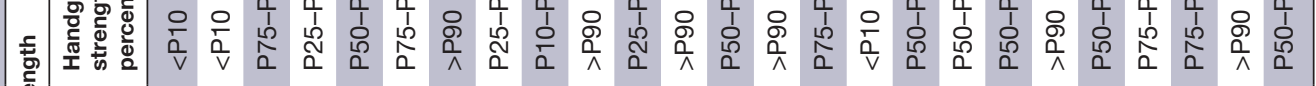

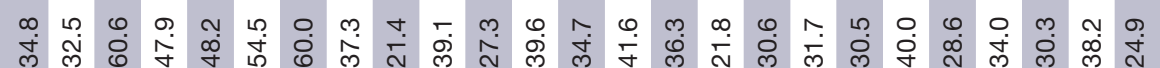

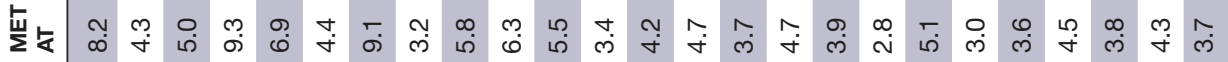

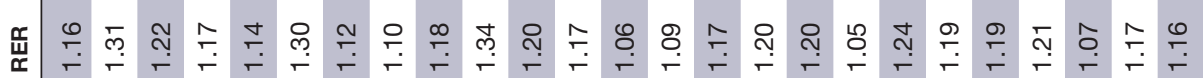

$\div \frac{\mathrm{d}}{\mathrm{d}}$

䍃递

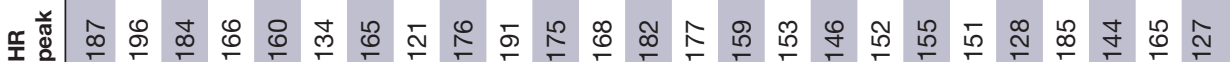

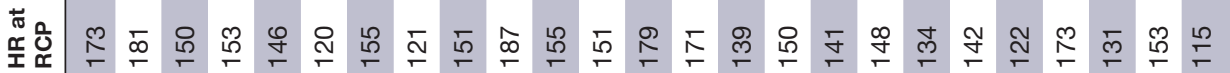

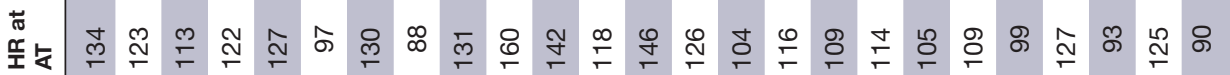

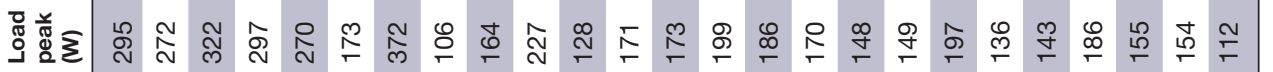

这

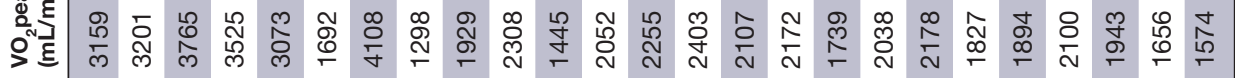

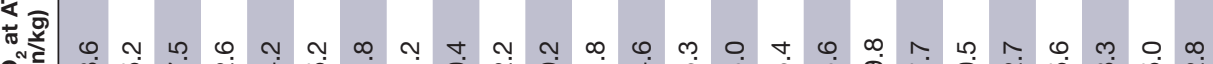

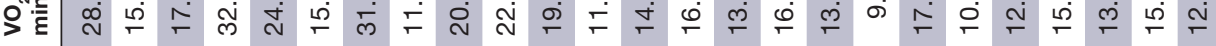

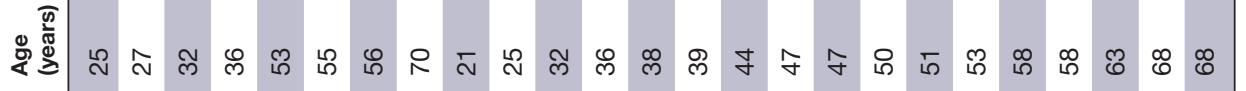

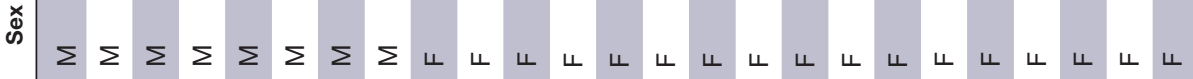

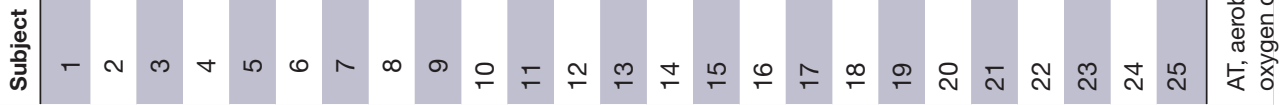




\begin{tabular}{|c|c|c|c|}
\hline & Study sample & Reference values & Difference \\
\hline \multicolumn{4}{|l|}{$\begin{array}{l}\mathrm{VO}_{2} \text { peak }(\mathrm{mL} / \mathrm{min} \text {, } \\
\text { mean } \pm \mathrm{SD})\end{array}$} \\
\hline Total $(n=25)$ & $2298 \pm 745$ & $2712 \pm 736^{\star}$ & $\begin{array}{l}-414 \pm 510 \\
(p<0.001)\end{array}$ \\
\hline Men $(n=8)$ & $2978 \pm 983$ & $3467 \pm 635^{*}$ & $\begin{array}{l}-489 \pm 764 \\
(p=0.113)\end{array}$ \\
\hline Women $(n=17)$ & $1978 \pm 265$ & $2357 \pm 466^{*}$ & $\begin{array}{l}-379 \pm 362 \\
(p=0.001)\end{array}$ \\
\hline \multicolumn{4}{|c|}{$\begin{array}{l}\mathrm{VO}_{2} \text { peak }(\mathrm{mL} / \mathrm{min} / \mathrm{kg} \\
\text { mean } \pm \mathrm{SD})\end{array}$} \\
\hline Total $(n=25)$ & $29.0 \pm 9.4$ & & \\
\hline Men $(n=8)$ & $36.3 \pm 12.3$ & & \\
\hline Women $(n=17)$ & $25.5 \pm 5.3$ & & \\
\hline \multicolumn{4}{|c|}{ ACSM category (n (\%)) } \\
\hline \multicolumn{4}{|l|}{ Total $(n=25)$} \\
\hline Very poor & $15(60)$ & & \\
\hline Poor & $3(12)$ & & \\
\hline Fair & $4(16)$ & & \\
\hline Good & $1(4)$ & & \\
\hline Excellent & $1(4)$ & & \\
\hline
\end{tabular}

*Based on the best-fitting polynomial regression model determined using cycle ergometry in a healthy Dutch population. ${ }^{14}$

ACSM, American College of Sports Medicine; CANS, complaints of arm, neck and/or shoulder; $\mathrm{VO}_{2}$, oxygen consumption.

$2712 \pm 736 \mathrm{~mL} / \mathrm{min}$. Compared with this reference value, $\mathrm{VO}_{2}$ peak of study sample was on average $414 \pm 510 \mathrm{~mL} /$ min lower than expected by the model $(\mathrm{p}<0.001)$ (table 3). Mean $\mathrm{VO}_{2}$ peak of the study sample was $85 \%$ of the value predicted by the model.

According to ACSM categories, cardiorespiratory fitness was poor or very poor in 18 patients $(72 \%)$, fair in 4 patients $(16 \%)$ and good to superior in 3 patients $(12 \%)$ (table 3$)$.

\section{Muscular strength}

Mean handgrip strength of men was $47.0 \pm 11.1 \mathrm{kgf}$ and of women was $32.4 \pm 6.3 \mathrm{kgf}$. Handgrip strength of $25 \%$ of men and $12 \%$ of women was below P25 of the sex and age specific reference values (figure $2 \mathrm{~A}$ ).

\section{Body composition}

BMI of the total study sample was $26.4 \pm 5.4 \mathrm{~kg} / \mathrm{m}^{2}$ $\left(24.2 \pm 2.6 \mathrm{~kg} / \mathrm{m}^{2}\right.$ for men and $27.4 \pm 6.1 \mathrm{~kg} / \mathrm{m}^{2}$ for women). According to BMI categories, $44 \%$ of the study sample (25\% of men and $53 \%$ of women) was overweight or obese (BMI: $\geq 25 \mathrm{~kg} / \mathrm{m}^{2}$ ). Compared with the general Dutch population, in the study sample, the proportion of overweight or obese men was lower and of overweight or obese women was slightly higher (figure 2B). FFMI of $38 \%$ of men and $71 \%$ of women was above P75 of the sex and age-specific reference values (figure $2 \mathrm{C}$ ).

\section{Health-related physical fitness: correlations with symptom severity and upper limb function and physical activity}

The relationship between health-related physical fitness components, symptom severity and upper limb function (QuickDASH, PRWHE, PDI and NRS-Pain) and physical activity (NNGB and Fitnorm) is presented in table 4. Correlations between health-related physical fitness components and self-reported symptom severity and upper limb function were not significant, apart from a moderate positive correlation between BMI and PDI. A moderate positive correlation was observed between cardiorespiratory fitness and physical activity measured by Fitnorm, but not NNGB. Physical activity was not significantly correlated with handgrip strength, nor with body composition.

\section{DISCUSSION}

Cardiorespiratory fitness in patients with complaints of hand, wrist, forearm and elbow was lower than in matched healthy references, both by direct comparison of $\mathrm{VO}_{2}$ peak using a model and through categorisation, according to ACSM criteria. ${ }^{15}$ These findings concur with a study reporting a lower $\mathrm{VO}_{2} \max$ in patients with chronic low back pain. Studies using submaximal methods to assess cardiorespiratory fitness also observed lower fitness levels in patients with musculoskeletal disorders compared with healthy controls. ${ }^{734}$ Maximal handgrip strength in our sample seemed similar to the general population, with a fairly equal distribution of handgrip strength over reference value percentiles. This finding contradicts those of others, because lower handgrip strength is described in several hand conditions. ${ }^{35}{ }^{36}$ Even though the majority of the study sample indicated involvement of both hands, apparently handgrip strength of at least
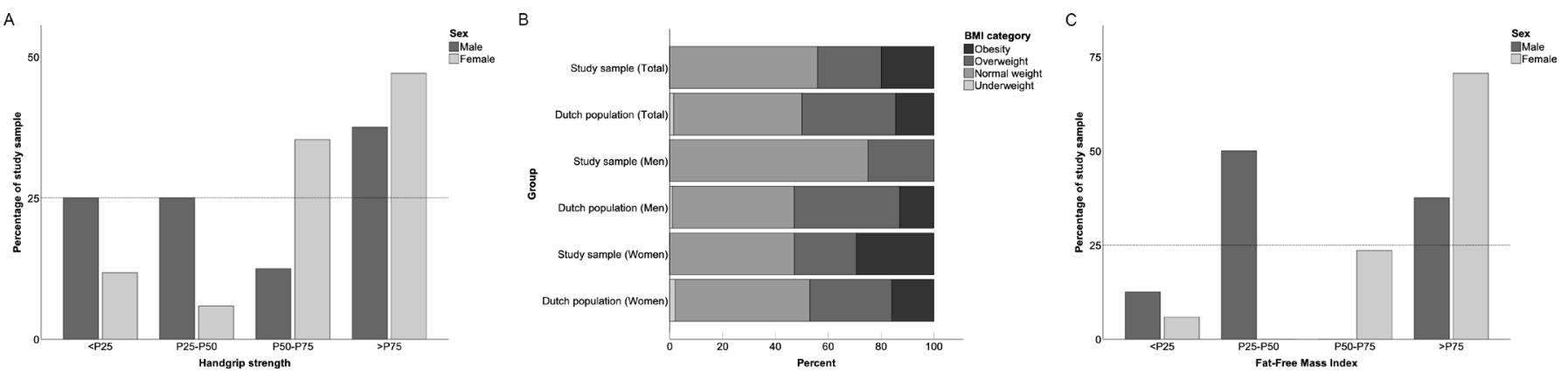

Figure 2 (A) Handgrip strength: distribution over percentiles of reference values. (B) Comparison of BMI categories. BMI, body mass index. (C) Fat-Free Mass Index: distribution over percentiles of reference values. 
Table 4 Spearman's partial correlations between health-related physical fitness, symptom severity and upper limb function and physical activity, controlled for sex and age

\begin{tabular}{|c|c|c|c|c|c|}
\hline & \multicolumn{2}{|c|}{ Cardiorespiratory fitness } & \multirow{2}{*}{$\begin{array}{l}\text { Muscular strength } \\
\text { Handgrip strength }\end{array}$} & \multicolumn{2}{|l|}{ Body composition } \\
\hline & $\mathrm{VO}_{2}$ peak & ACSM category & & BMI $\left(\mathrm{kg} / \mathrm{m}^{2}\right)$ & FFMI \\
\hline \multicolumn{6}{|c|}{ Symptom severity and upper limb function } \\
\hline QuickDASH Questionnaire & $-0.31(p=0.155)$ & $-0.26(p=0.227)$ & $-0.24(p=0.268)$ & $0.38(p=0.073)$ & $0.17(p=0.444)$ \\
\hline PRWHE questionnaire & $-0.19(p=0.376)$ & $-0.21(p=0.340)$ & $-0.24(p=0.269)$ & $0.30(p=0.159)$ & $0.21(p=0.344)$ \\
\hline PDI & $-0.30(p=0.167)$ & $-0.20(p=0.353)$ & $-0.21(p=0.349)$ & $0.48(p=0.022)^{\star}$ & $0.30(p=0.169)$ \\
\hline NRS-Pain & $-0.10(p=0.640)$ & $-0.23(p=0.289)$ & $-0.12(p=0.574)$ & $0.24(p=0.268)$ & $0.25(p=0.260)$ \\
\hline \multicolumn{6}{|l|}{ Physical activity } \\
\hline NNGB & $0.20(p=0.354)$ & $0.06(p=0.781)$ & $-0.138(p=0.530)$ & $-0.19(p 0.380)$ & $-0.12(p 0.589)$ \\
\hline Fitnorm & $0.58(p=0.004)^{\star}$ & $0.54(p=0.008)^{*}$ & $0.174(p=0.428)$ & $-0.23(\mathrm{p} 0.301)$ & $-0.06(p 0.790)$ \\
\hline
\end{tabular}

*Statistically significant $(p<0.05)$.

ACSM, American College of Sports Medicine; BMI, body mass index; FFMI, Fat-Free Mass Index; NNGB, Nederlandse Norm Gezond Bewegen (Dutch Healthy Physical Activity Guidelines); NRS-Pain, Numeric Pain Rating Scale; PDI, Pain Disability Index; PRWHE, Patient-Rated Wrist/Hand Evaluation; QuickDASH, Quick Disabilities of the Arm, Shoulder and Hand.

one of the hands is preserved. Also, a reduction in handgrip strength in the study sample might be too little to be detected by a change in quartiles. The use of a grip strength ratio seems valid to assess the difference in grip strength between both hands, but its usefulness in bilaterally affected patients is unknown. ${ }^{35}$ The distribution of BMI categories in this study sample seems to differ slightly from the general Dutch adult population, with less overweight men and more obese women than expected from general population data. ${ }^{19}$ FFMI in women in this study sample was higher than the reference values. This might be explained by their BMI, which was on average higher than in the reference population. ${ }^{21}$ FFMI values will be higher with greater weight and $\mathrm{BMI} .^{20}$

The majority of correlations between the health-related physical fitness and self-reported symptom severity and upper limb function were absent or low. Others have reported a moderate association between poorer self-reported physical fitness and non-specific work-related upper limb disorders, in patients with seemingly lower symptom severity and shorter duration of complaints. ${ }^{10}$ It is unsure why we did not find such a relationship, but the limited validity of self-reported physical fitness assessed in the previous study (compared with performance-based physical fitness) might be an explanation. $^{37}$

Cardiorespiratory fitness and physical activity (Fitnorm) were moderately positively correlated, which is consistent with other study results. ${ }^{38-40}$ The relationship between cardiorespiratory fitness and physical activity might be dose dependent, because cardiorespiratory fitness was better in patients meeting the Fitnorm criteria, but not in patients meeting the NNGB criteria. The most important difference between Fitnorm and NNGB is the exercise intensity, which is higher for the Fitnorm. More substantial increases of aerobic capacity have been reported with higher intensity training programmes. ${ }^{41-43}$ The proportion of patients in our study meeting NNGB $(68 \%)$ or Fitnorm (32\%) corresponded to the Dutch general population, of which 59\% meet NNGB criteria and $25 \%$ meet Fitnorm criteria. ${ }^{19}$
No relationship between handgrip strength and upper limb function was found. Moderate negative correlations between handgrip strength and both QuickDASH and PRWHE Questionnaires have been described before. ${ }^{2444}$ A probable explanation for the absence of a strong correlation in this study sample is the use of maximum handgrip strength of either hand instead of the affected hand. We found a moderate positive correlation between BMI and PDI in this study sample. A similar relationship between BMI and pain and disability has been found in patients with shoulder problems. ${ }^{45}$ While the mechanisms need further unravelling, especially obese patients seem to be at risk for chronic musculoskeletal pain. The relationship between pain and obesity seems to play a role in both specific as non-specific conditions, but the mechanisms involved may differ. ${ }^{46} 47$ Available models illustrate the complex interaction between obesity, pain, disability and many more factors. ${ }^{48}$ We are unaware of reports on this matter in patients with complaints of hand, wrist, forearm and elbow to compare our results to.

Longitudinal studies investigating the relationship between health-related physical fitness in patients with musculoskeletal disorders are unknown and, therefore, one can only speculate about causality. Causality in both directions has been suggested: increased risk of CANS in persons with lower health-related physical fitness or reduced physical fitness due to activity limitations in patients with CANS. Association of better cardiorespiratory fitness with less musculoskeletal pain has been described before and physical activity might reduce musculoskeletal complaints. ${ }^{849}$ Due to our cross-sectional design, we were unable to shed light on causality. However, the causal relationship needs attention in further research, since such data are needed to develop or adjust (preventive) treatment programmes.

\section{Strengths and limitations}

The most considerable methodological strengths are the simultaneous analysis of several aspects of health-related 
physical fitness, and especially the assessment of cardiorespiratory fitness using the gold standard, CPET, to measure $\mathrm{VO}_{2}$ peak during maximal effort. We are unaware of other studies reporting objectively measured cardiorespiratory fitness in patients with upper limb disorders. Because $93 \%$ of the subjects who started CPET reached maximal effort and no serious adverse events occurred, safety and tolerability of CPET in this patient sample are not refuted, given the protocol as applied here.

The small sample size might pose a limitation and the study might be underpowered to demonstrate statistically significant relationships between health-related physical fitness and parameters such as symptom severity and upper limb function. However, because this was an exploratory study, the results may be used to calculate sample sizes for future studies. Because of the exploratory nature of this study, we did not correct for a type I error, even though multiple correlations were explored. Other factors influencing health-related physical fitness can be determined that were not assessed in this study, such as the presence of cardiovascular and pulmonary comorbidity. Furthermore, self-report measures of physical activity might have limited validity. ${ }^{50}$

Reference values for components of health-related physical fitness appeared to be diverse or lacking (depending on source population characteristics) and this hindered comparison of the study sample to the general population. However, the description of multiple characteristics of individual subjects facilitates comparison with any desired reference value.

\section{CONCLUSIONS}

Cardiorespiratory fitness of this sample of patients with CANS was lower than reference values. Handgrip strength and body composition did not seem to differ from reference values. Cardiorespiratory fitness was positively correlated with physical activity. A higher BMI was correlated with greater disability, but most other relationships between health-related physical fitness and symptom severity and upper limb function were low or non-existent.

One might interpret very cautiously that, in this sample, levels of cardiorespiratory fitness seem to be determined by physical activity and not by symptom severity nor upper limb function.

Physicians and therapists should pay attention to health-related physical fitness (especially cardiorespiratory fitness and BMI) in patients with CANS. Even though the causal relationship is still unknown, interventions to improve physical activity (frequency, duration and intensity to meet the Fitnorm) could be considered.

Suggestions for further research include repetition of a similar study in a larger clinical sample, to assess changes in health-related physical fitness over the course of CANS (from onset to improvement) and to assess the effect of interventions aimed at improving health-related physical fitness (both on physical fitness itself as on symptom severity and upper limb function). The ability to engage in physical activity (eg, work and sports) and the actual duration and intensity thereof might also be studied in greater detail.

Contributors All authors meet the ICMJE authorship criteria.

Funding The authors have not declared a specific grant for this research from any funding agency in the public, commercial or not-for-profit sectors.

Competing interests None declared.

Patient and public involvement Patients and/or the public were not involved in the design, or conduct, or reporting, or dissemination plans of this research.

\section{Patient consent for publication Not required}

Ethics approval The study has been performed according to the Declaration of Helsinki and amendments. The study was approved by the medical ethical committee of the University Medical Center Groningen (2015/115).

Provenance and peer review Not commissioned; externally peer reviewed. Data availability statement Data are available upon reasonable request.

Open access This is an open access article distributed in accordance with the Creative Commons Attribution Non Commercial (CC BY-NC 4.0) license, which permits others to distribute, remix, adapt, build upon this work non-commercially, and license their derivative works on different terms, provided the original work is properly cited, appropriate credit is given, any changes made indicated, and the use is non-commercial. See: http://creativecommons.org/licenses/by-nc/4.0/.

\section{ORCID iD}

Redmar J Berduszek http://orcid.org/0000-0001-7268-8762

\section{REFERENCES}

1 Huisstede BMA, Wijnhoven HA, Bierma-Zeinstra SM, et al. Prevalence and characteristics of complaints of the arm, neck, and/ or shoulder (cans) in the open population. Clin J Pain 2008;24:253-9.

2 Huisstede BMA, Miedema HS, Verhagen AP, et al. Multidisciplinary consensus on the terminology and classification of complaints of the arm, neck and/or shoulder. Occup Environ Med 2007;64:313-9.

3 Staal JB, de Bie RA, Hendriks EJM. Aetiology and management of work-related upper extremity disorders. Best Pract Res Clin Rheumatol 2007;21:123-33.

4 Caspersen CJ, Powell KE, Christenson GM. Physical activity, exercise, and physical fitness: definitions and distinctions for healthrelated research. Public Health Rep 1985;100:126-31 http://www. ncbi.nlm.nih.gov/pubmed/3920711

5 Duque I, Parra J-H, Duvallet A. Maximal aerobic power in patients with chronic low back pain: a comparison with healthy subjects. Eur Spine J 2011;20:87-93.

6 Tveter AT, Dagfinrud H, Moseng T, et al. Health-related physical fitness measures: reference values and reference equations for use in clinical practice. Arch Phys Med Rehabil 2014;95:1366-73.

7 Moseng T, Tveter AT, Holm I, et al. Patients with musculoskeletal conditions do less vigorous physical activity and have poorer physical fitness than population controls: a cross-sectional study. Physiotherapy 2014;100:319-24.

8 Moberg LL, Lunde L-K, Koch M, et al. Association between VO handgrip strength, and musculoskeletal pain among construction and health care workers. BMC Public Health 2017;17:272.

9 Fletcher GF, Ades PA, Kligfield P, et al. Exercise standards for testing and training: a scientific statement from the American heart association. Circulation 2013;128:873-934.

10 Van Eijsden-Besseling MDF, van Attekum A, de Bie RA, et al. Pain catastrophizing and lower physical fitness in a sample of computer screen workers with early non-specific upper limb disorders: a casecontrol study. Ind Health 2010;48:818-23.

11 van Hulst R, van Oostrom SH, Ostelo RWJG, et al. Long-term patterns of chronic complaints of the arms, neck, and shoulders and their determinants--the Doetinchem Cohort Study. Pain 2016;157:1114-21.

12 American Thoracic Society, American College of Chest Physicians. ATS/ACCP statement on cardiopulmonary exercise testing. Am J Respir Crit Care Med 2003;167:211-77.

13 Daniel J. Sampling essentials: practical guidelines for making sampling choices. SAGE Publications, Inc, 2012.

14 Mylius CF, Krijnen WP, van der Schans CP, et al. Peak oxygen uptake reference values for cycle ergometry for the healthy Dutch 
population: data from the LowLands fitness registry. ERJ Open Res 2019;5:00056-2018-2018.

15 Riebe D, Ehrman JK, Liguori G. ACSM's guidelines for exercise testing and prescription. 10th edn. Philadelphia, PA: Wolters Kluwer/ Lippincott Williams \& Wilkins, 2017.

16 Trampisch US, Franke J, Jedamzik N, et al. Optimal jamar dynamometer handle position to assess maximal isometric hand grip strength in epidemiological studies. J Hand Surg Am 2012;37:2368-73.

17 Dodds RM, Syddall HE, Cooper R, et al. Grip strength across the life course: normative data from twelve British studies. PLoS One 2014;9:e113637.

18 National Heart, Lung and BI. Clinical guidelines on the identification, evaluation, and treatment of overweight and obesity in adults: Executive summary. expert panel on the identification, evaluation, and treatment of overweight in adults. Am J Clin Nutr 1998;68:899-917.

19 CBS StatLine. Leefstijl en (preventief) gezondheidsonderzoek; persoonskenmerken. Available: https://statline.cbs.nl/. Published 2020 [Accessed 29 Jan 2021].

20 Kyle UG, Schutz Y, Dupertuis YM, et al. Body composition interpretation. contributions of the fat-free mass index and the body fat mass index. Nutrition 2003;19:597-604.

21 Schutz Y, Kyle UUG, Pichard C. Fat-free mass index and fat mass index percentiles in Caucasians aged 18-98 Y. Int J Obes Relat Metab Disord 2002;26:953-60.

22 VanderZee KI, Sanderman R, Heyink JW, et al. Psychometric qualities of the RAND 36-Item health survey 1.0: a multidimensional measure of general health status. Int J Behav Med 1996;3:104-22.

23 Hays RD, Sherbourne CD, Mazel RM. The RAND 36-Item health survey 1.0. Health Econ 1993;2:217-27.

24 Kennedy CA, Beaton DE, Smith P, et al. Measurement properties of the QuickDASH (disabilities of the arm, shoulder and hand) outcome measure and cross-cultural adaptations of the QuickDASH: a systematic review. Qual Life Res 2013;22:2509-47.

25 El Moumni M, Van Eck ME, Wendt KW, et al. Structural validity of the Dutch version of the patient-rated wrist evaluation (PRWE-NL) in patients with hand and wrist injuries. Phys Ther 2016;96:908-16.

26 MacDermid JC, Tottenham V. Responsiveness of the disability of the arm, shoulder, and hand (DASH) and patient-rated wrist/hand evaluation (PRWHE) in evaluating change after hand therapy. $J$ Hand Ther 2004;17:18-23.

27 Soer R, Köke AJA, Vroomen PCAJ, et al. Extensive validation of the pain disability index in 3 groups of patients with musculoskeletal pain. Spine 2013;38:E562-8.

28 Hjermstad MJ, Fayers PM, Haugen DF, et al. Studies comparing numerical rating scales, verbal rating scales, and visual analogue scales for assessment of pain intensity in adults: a systematic literature review. J Pain Symptom Manage 2011;41:1073-93.

29 Kemper HCG, Ooijendijk WTM, Stiggelbout M. Consensus over de Nederlandse norm voor gezond bewegen. Tijdschr voor gezondheidswetenschappen 2000;78:180-3 https://repository. tudelft.nl/view/tno/uuid:a8cabc4a-e5d2-422e-aea9-449becabd5a4

30 American College of sports medicine position stand. American college of sports medicine position stand. The recommended quantity and quality of exercise for developing and maintaining cardiorespiratory and muscular fitness in healthy adults. Med Sci Sports Exerc 1990;22:265-74.
31 van Abbema R, Lakke SE, Reneman MF, et al. Factors associated with functional capacity test results in patients with non-specific chronic low back pain: a systematic review. J Occup Rehabil 2011;21:455-73.

32 Soer R, Brouwer S, Geertzen JH, et al. Decline of functional capacity in healthy aging workers. Arch Phys Med Rehabil 2012;93:2326-32.

33 Schober P, Boer C, Schwarte LA. Correlation coefficients: appropriate use and interpretation. Anesth Analg 2018;126:1763-8.

34 Yalcinkaya H, Ucok K, Ulasli AM, et al. Do male and female patients with chronic neck pain really have different health-related physical fitness, depression, anxiety and quality of life parameters? Int $J$ Rheum Dis 2017;20:1079-87.

35 Beumer A, Lindau TR. Grip strength ratio: a grip strength measurement that correlates well with DASH score in different hand/ wrist conditions. BMC Musculoskelet Disord 2014;15:336.

36 Langer D, Maeir A, Michailevich M, et al. Evaluating hand function in clients with trigger finger. Occup Ther Int 2017;2017:1-8.

37 van Heuvelen MJG, Kempen GIJM, Ormel J, et al. Self-reported physical fitness of older persons: a substitute for performancebased measures of physical fitness? J Aging Phys Act 1997:5:298-310.

38 Mundwiler J, Schüpbach U, Dieterle T, et al. Association of occupational and leisure-time physical activity with aerobic capacity in a working population. PLoS One 2017;12:e0168683

39 Ong TC, Sothy SP. A comparative study of the maximum oxygen uptake of regularly exercising and non-exercising health adult men in sedentary occupations. Occup Med 1992;42:120-4.

40 Byrd BR, Keith J, Keeling SM, et al. Personalized moderate-intensity exercise training combined with high-intensity interval training enhances training responsiveness. Int J Environ Res Public Health 2019;16:2088.

41 Helgerud J, Høydal K, Wang E, et al. Aerobic high-intensity intervals improve VO2max more than moderate training. Med Sci Sports Exerc 2007;39:665-71.

42 Milanović Z, Sporiš G, Weston M. Effectiveness of high-intensity interval training $(\mathrm{HIT})$ and continuous endurance training for VO2max improvements: a systematic review and meta-analysis of controlled trials. Sports Med 2015;45:1469-81.

43 Sultana RN, Sabag A, Keating SE, et al. The effect of lowvolume high-intensity interval training on body composition and cardiorespiratory fitness: a systematic review and meta-analysis. Sports Med 2019:49:1687-721.

44 Mehta SP, MacDermid JC, Richardson J, et al. A systematic review of the measurement properties of the patient-rated wrist evaluation. J Orthop Sports Phys Ther 2015;45:289-98.

45 Zahorska-Markiewicz B, Kucio C, Pyszkowska J. Obesity and pain. Hum Nutr Clin Nutr 1983;37:307-10.

46 Narouze S, Souzdalnitski D. Obesity and chronic pain: systematic review of prevalence and implications for pain practice. Reg Anesth Pain Med 2015;40:91-111.

47 Okifuji A, Hare BD. The association between chronic pain and obesity. J Pain Res 2015;8:399-408.

48 McVinnie DS. Obesity and pain. Br J Pain 2013;7:163-70.

49 Blangsted AK, Søgaard K, Hansen EA, et al. One-year randomized controlled trial with different physical-activity programs to reduce musculoskeletal symptoms in the neck and shoulders among office workers. Scand J Work Environ Health 2008;34:55-65.

50 Shephard RJ. Limits to the measurement of habitual physical activity by questionnaires. Br J Sports Med 2003;37:197-206. 